\title{
Sobresalir:
}

\section{Latino Parent Perspectives on New Latino Diaspora Schools}

\author{
Sarah Gallo and Stanton Wortham \\ University of Pennsylvania
}

U. S. A.

Although many have documented the high value Latino families place on education, prevalent discourses nonetheless characterize Latino immigrant parents as not caring about their children's education. This paper describes the practice-based components of a participatory action research project in which we created a collaborative film, intended for use in teacher professional development, which counters these discourses. In the film, Mexican immigrant parents in one New Latino Diaspora community discuss their experiences with schools. Parents' stories give teachers an opportunity to re-think their relationships with and impressions of Mexican immigrant families.

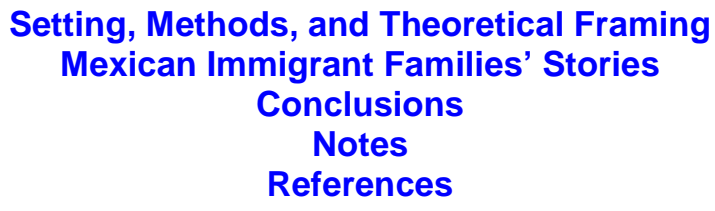

As Latinos move to areas of the United States that have not had Latino residents, towns across the country are experiencing rapid and unfamiliar demographic changes. Marshall, a suburban community of approximately 35,000 in the Northeastern United States, has gone from about 100 Mexicanorigin residents in 1990 to about 8,000 in 2010 (U.S. Census Bureau, 2010). In $2011,27 \%$ of the district's students were Latino, including $44 \%$ of kindergarteners - almost all of Mexican origin. Marshall is part of the New Latino Diaspora (NLD) (Murillo, 2002; Villenas, 2001), a demographic phenomenon in which increasing numbers of Latino immigrants are moving to regions of the United States that have not traditionally been home to Latinos. This rapid growth in the (largely) Mexican immigrant population presents practical and symbolic challenges both for longstanding residents and newcomers, as longer-term residents live alongside Latinos for the first time (Gouveia, Carranza, \& Cogua, 2005; Grey \& Woodrick, 2005). The newness of the immigrant population presents both challenges and opportunities (Millard \& Chapa, 2004; Wortham, Murillo, \& Hamann, 2002; Zúñiga \& Hernández-León, 2005). Hosts and newcomers sometimes forge productive relationships, but residents also commit symbolic and physical violence against immigrants (Grey \& Woodrick, 2005; Murillo, 2002; Rich \& Miranda, 2005). 
This violence is especially prevalent within the current climate of heightened anti-immigrant sentiments. In Marshall and elsewhere across the United States, anti-immigrant discourses circulate about immigrants' "abuses" of public resources like schools. For example, erroneous assumptions persist that immigrants do not pay taxes, thereby creating a huge economic burden on U.S. citizens who have to pay for immigrant schooling. In addition, although many scholars have demonstrated the high value Latino families place on education (Ceballo, 2004; Delgado-Gaitan, 1991; Suárez-Orozco \& Suárez-Orozco, 2001; Trueba, 1999; Valdés, 1996), some discourses also characterize Latino immigrant families as not caring about their children's education-perhaps because some Latino parents do not participate in their children's schooling in mainstream ways (Chavkin, 1989; Moles, 1993; Torres-Guzmán, 1991).

In this article we describe the practice-based components of a participatory action research project that we conducted between 2008-2010, together with Marshall educators and immigrant families, to increase Spanishspeaking parents' involvement in local schools. The larger project had several components, including the development of school-based resource rooms staffed with bilingual educators and the creation of a Latino parent leadership group, which was initially led by educators and researchers but shifted to collaborative leadership with immigrant parents over time (See Gallo \& Wortham, in press, for further discussion).

In this article we focus on another component of the project, the creation of a collaborative film titled Sobresalir ${ }^{1}$ : Latino Parent Perspectives on New Latino Diaspora Schools. In this film, which was made by researchers and educators as a tool for teacher professional development in Marshall, Mexican immigrant parents share their perspectives on working with local schools. The film draws from a corpus of video-recorded interviews with a dozen immigrant families who were invited to share their stories, experiences, and suggestions for teachers and schools. Mexican immigrant parents from the Latino parent leadership group watched various versions of the film and provided feedback on the content. In the final version parents share their stories and perspectives, presenting alternatives to dominant discourses about Mexican immigrant parents' lack of engagement with schools.

In this article we briefly describe the local setting, our research methods, and conceptual approach. Then we present portions of the parents' stories that appear in the film - touching on themes of homework, values, parent-teacher communication, and equitable treatment in schools. These stories illustrate the unique resources and perspectives that Mexican immigrant families bring to their children's education in U.S. schools and underline the high priority they place on education. Having now shown the film over two years in teacher professional development sessions in Marshall, and having collected feedback from teachers after these viewings, our analysis below also includes discussion of how teachers reacted to the immigrant parents' stories in the film. Thus, we show how the medium of film can be a tool for increasing parent involvement for minority families and how it has the potential to challenge anti-immigrant discourses. In 
our conclusion, we discuss how this collaborative parent involvement initiative might provide lessons to other educators working with newly arrived immigrant families.

\section{Setting, Methods, and Theoretical Framing}

\section{Marshall}

Marshall is a suburb of approximately 35,000 people that has attracted thousands of Latino immigrants over the past two decades. The newcomers work mostly in landscaping, construction, retail, and restaurants. The U.S. Census shows dramatic changes in the proportions of racial and ethnic groups in Marshall between 1990 and 2010-going from 71\% white, 26\% AfricanAmerican, and 3\% Latino to 32\% white, 35\% African-American, and 28\% Latino. We have found from our ethnographic research in Marshall over the past eight years that the majority of Latinos are newly arrived immigrants from Mexico. Latino students, the vast majority of Mexican heritage, now make up $27 \%$ of students in the school district. Although there are no specific statistics published on Marshall educators, from our extensive experience in the school district we have found that most Marshall educators are European American women who live in the wealthier suburbs near Marshall. Few have experience with multilingual settings. Most are monolingual English speakers and have only recently begun working with newcomers from Mexico and their families.

Educational disparities are evident in the Marshall Area School District (MASD). In recent years, about a third of Latino and African American students scored at the lowest level, "below basic," on state-wide standardized tests, compared with about $15 \%$ of whites. Marshall schools had limited previous experience working with immigrant students and have faced challenges in figuring out how to effectively educate a changing student population with an increase in English Language Learners who come predominantly from Mexican immigrant families. As in many NLD communities, the arrival of a growing Latino community has resulted in mixed reactions in the schools and the town-but we have found that these reactions are generally more positive than in many similar communities. The schools, the police, health care providers, the government, and other institutions in Marshall are not always friendly, but they are often more welcoming than other NLD towns (Wortham, Mortimer, \& Allard, 2009).

\section{Collaborative Parent Involvement Initiatives}

In 2008 we approached the school district with a proposal to work collaboratively on improving education for immigrant children. At that time we had been doing ethnography in local schools, immigrant families' homes, and the 
larger community for over three years. District leadership agreed to a proposed collaborative action project between researchers and educators on immigrant children and education. We asked the administrators to pick the specific topic, and they chose to focus on increasing Spanish-speaking parents' involvement with their children's schools. All of the families that ended up participating in the collaborative projects were from Mexico, and all of the parents were Spanishdominant.

For a more extensive discussion of the larger collaborative action research project and the shift from researcher-centered to immigrant parents-initiated activity, see Gallo and Wortham (in press). We began the larger project with two initiatives. First, in response to parents' uncertainty about how to help with their children's homework, we collaborated with teachers at four elementary schools to create weekly Spanish-medium resource rooms in which parents and their children could bring topics of concern, ask questions regarding homework, and receive English lessons. Over time the resource rooms shifted from a site of teacher-centered expertise to spaces where teachers, immigrant parents, and researchers collaborated on content and implementation. Through their participation in the resource rooms, some students increased their academic achievement and some teachers and parents developed close interpersonal relationships, which helped many immigrant parents become more comfortable and engaged with school-based activities. For example, several parents who participated in the weekly resource rooms at one school began taking on leadership roles at school events such as classroom celebrations for the "Day of the Child." Second, drawing upon Delgado-Gaitan's (2001) work with the Comité de Padres Latinos, we worked with educators to create a monthly district-wide Spanish-medium parent forum, in which Spanish-speaking parents could discuss their concerns and suggestions about local schools. Over time the district-wide parent forum led to the emergence of a parent leadership group that met more frequently, secured the participation of the Superintendent in monthly meetings, and took over the meetings such that our participation was no longer necessary. Thus, the parent forum also shifted from an educator and researcher-centered collaboration into one led by Mexican immigrant parents. The creation of the film Sobresalir was spearheaded by the university researchers and grew out of this new collaborative structure with educators and immigrant families in Marshall.

\section{Sobresalir}

Working with families from the parent group and educators within the district, we created a film that draws from a corpus of video-recorded interviews with a dozen Mexican immigrant families. The idea for this film originated in meetings with school administrators, when Stanton commented that it would be nice if educators could speak directly with immigrant parents and hear their perspectives. Despite having no background in film, he said that a subtitled film presenting parents' voices in their own words would be a good mechanism. The 
administrators asked if he could create such a film, and he then enlisted Sarah and two other colleagues whose complementary skills facilitated production of the film. Footage was collected by a team of researchers who interviewed immigrant parents, then met with immigrant parents and educators for feedback on emerging themes and then on draft versions of the film. The producers of the film were Stanton Wortham, who oversaw the project; Sarah Gallo, who made many contacts and did several interviews; Carlos Martinez, who also conducted several interviews; and Noam Osband, who did the video editing.

Bilingual doctoral students conducted all of the interviews, inviting parents to share their experiences and perspectives on local schools, with local educators as their intended audience. After video recording a dozen open-ended interviews with immigrant parents, the team, led by we the authors, logged the interviews and looked for emergent themes. We selected themes through a process of coding much like that described in qualitative methods texts (e.g., LeCompte \& Schensul, 1999). We selected representative segments and showed these to the parent group for feedback. We also shot footage of the local town and schools, to use as the background imagery ("B-roll") in the film. After several rounds of editing and feedback from relevant individuals, the final version was screened for the entire parent forum, and they gave it their enthusiastic approval. Sobresalir has been used by the Marshall school district as a professional development tool since 2010 and has been viewed by at least half of the educators in local schools. During these professional development sessions, teachers filled out anonymous feedback sheets about their reactions to the film, and we summarize their reactions below. The film has also been used in other local districts, which have become home to Latino students in recent years. Copies of the DVD were distributed to all families who appear in the film.

\section{Theoretical Framing}

Our approach to "parent involvement" differs from traditional approaches. We adopt a "repertoires" approach (Gutiérrez \& Rogoff, 2003; Rymes, 2010; See Gallo \& Wortham, in press, for further discussion). In traditional parent involvement initiatives, educators want parents to be "involved" by helping with the typical activities of schooling, assuming that these activities are universally accepted and optimal for all children —and that "they" (immigrants) should learn to educate like "us" (longstanding residents and local educators). We argue that students often need more heterogeneous educational practices and that parent involvement requires change both by educators and by immigrant families. It is certainly the case that Mexican immigrant parents and children can benefit from learning various repertoires in English-how to talk about academic subject matter, how to make requests of educational professionals, and how to participate in politics. However, a school can more productively involve immigrant parents if educators themselves master new and varied repertoires for communicating with immigrants, and if they recognize that they can build on 
repertoires that immigrant parents and children already contro—such as the deep concern local immigrant parents have for their children's education. A repertoires approach focuses on each individual's history of engagement with cultural practices, which are partly shared across national groups or language communities but which also include divergent capacities and heterogeneous ideals (Gutiérrez \& Rogoff, 2003). Thus, although Mexican immigrants in Marshall may have many things in common, there is also important variation that can be better recognized by hearing a range of individual parents' perspectives and stories. The ultimate goal of a repertoires approach is to expand everyone's communicative toolkits and their dexterity in selecting an effective approach in a given situation (Gutiérrez \& Rogoff, 2003; Rymes, 2010).

With respect to parent involvement, a repertoires approach means that immigrant families should not simply internalize educators' repertoires by learning how to be involved with what the school has traditionally done. Instead, the goal is for each group to recognize and adopt some of the others' ways of talking about and doing things. Through such expansion, people become more able to interact productively with diverse others in various contexts. Like a funds of knowledge approach (Moll, Amanti, Neff, \& Gonzalez., 1992; Moll \& Gonzales, 2004), in which teachers become ethnographers to learn from their students' families via visits to their homes, a repertoires approach seeks out parents' unique beliefs, perspectives, and resources. Unlike funds of knowledge approaches to home visits, which include direct contact and relationship building among a few educators and immigrant parents, Sobresalir uses film as a medium to present a diverse group of parents' stories to a large group of local educators. Like funds of knowledge projects, this film provides an opportunity for teachers to learn from immigrant parents rather than evaluating how they do or do not measure up to traditional notions of parent involvement. Our goal was for educators to begin expanding their repertoires for understanding and working with Mexican immigrant parents by helping them understand alternative perspectives on the experiences, hopes, and strengths of Mexican families.

This approach aligns with Doucet's (2011) argument that parent involvement in school is a highly ritualized practice familiar to mainstream families and educators, yet one that tends to marginalize linguistically and culturally diverse families. Doucet describes how this marginalization often leads to decreased parent involvement by non-mainstream families, perpetuating the myth that they do not care about their children's education (Doucet, 2011). Through an examination of Haitian immigrant families' perspectives on parent involvement in the Boston area, she illustrates the alternative perspectives that these families hold on parent involvement and how their views are not widely understood by educators. As in Delgado-Gaitan's (2004) work on Latino familyschool involvement, Doucet (2011) suggests that instead of trying to get culturally and linguistically diverse families to "do" parent involvement in mainstream ways, educators should create new initiatives and more inclusive rituals. We hope that our film is an example of such an innovative approach as it created a forum for Mexican immigrant parents to share their views with local teachers. 
In creating the film we also drew upon action-oriented aspects of Critical Race Theory (CRT), such as Delgado's (1989) construct of counter-storytelling. Counter-stories illustrate alternatives to dominant discourses, such as Mexican immigrant parents' perspectives on their engagement with schools. Research from a critical race perspective seeks to account for the intersection of racism with other forms of subordination, such as sexism and classism, in order to challenge the status quo (Solorzano \& Bernal, 2001). This work involves listening with and learning from the experiences of people of color, such as the immigrant families who participated in the creation of this film, and counterstorytelling in particular is a tool to share the stories of voices often unheard (Solorzano \& Bernal, 2001). CRT has an activist component that aims to create transformation through heightened awareness and collective dialogue (Delgado \& Stefancic, 2001; Delgado-Gaitan, 2001). In the excerpts from their stories below, Mexican immigrant parents discuss their experiences with schools, addressing themes such as the challenges of helping with homework, their values related to educación, their desires for deeper parent-teacher communication, and hopes that their children will not be treated as inferior in local schools. Parents' stories help educators understand the contexts and resources that surround their decisions to participate in their children's schooling in traditional and nontraditional ways and offer an opportunity for teachers and administrators to reimagine their relationships with Mexican immigrant families.

\section{Mexican Immigrant Families' Stories}

Many Mexican immigrant families were excited about the opportunity to describe their experiences for local educators, although some were nervous about being on camera. Most parents already had relationships with the researchers conducting the interviews through their involvement in the resource rooms, in the parent leadership group, in local schools and service organizations, and/or in our ongoing ethnographic work. All of the interviews were conducted in Spanish in settings of the parents' choice, such as their homes, the local library, or their children's schools. After explaining the purpose of the film and gathering some basic background information, researchers invited parents to share stories - both good and bad-about their experiences with their children's schools. They were also invited to share advice for newly arrived parents from Mexico about working with local schools, advice for teachers about working with families from Mexico, and any ideas about how to improve the relationships between local schools and Latino families. In this section we share highlights from these conversations organized around the central themes of homework, values, parent-teacher communication, and equal opportunities. 


\section{Homework}

A regular part of the home-school relationship is the expectation that students will complete homework assignments (Mangual Figueroa, 2011). In Marshall, the majority of homework was sent home in English and often required the assistance of a parent to complete. Especially in the early grades, which focused on basic literacy practices like phonemic awareness and math skills, teachers often assumed that parents from Mexico would be able to assist their young children even when they had limited English skills. In the interviews, however, many parents described the struggles they had with homework assignments. For example, one father, seated in the dining room of his home next to his wife and two children, discussed his fear of doing more harm than good by trying to help with homework:

When we try to help our children, we sometimes trip them up instead of helping them. We read English but we don't know how to pronounce it. And instead of helping the child, we confuse him because we don't pronounce it correctly and that's where they have a problem. Because the child believes - A parent for a child is like his hero. So if the parent says, "This is how you say it," the child will believe that's how it's said. As a parent who doesn't have a complete grasp of English, it's difficult to help, and sometimes I feel frustrated because I don't know how to read it. In our case, we don't know how to read English and we can't help him. ${ }^{2}$

Parents discussed the challenges of helping their children with the isolated sounds and words used in early literacy assignments or reading to their children aloud in English. Most have no formal schooling in English and have not mastered the phonological complexities of the language, especially for assignments based on decontextualized phonics instruction.

Other parents discussed seeking out help at their children's school, describing how they often felt embarrassed for constantly asking questions of the few Spanish-speaking educators. For example, one mother, seated next to a small garden in her backyard on a warm summer afternoon, shared her frustration with helping with her son's homework:

I didn't know how to do the homework. I was in school every day asking Mr. Ramirez, "What must I do here? What do I need to do there?" And the teacher would tell me. But I was already embarrassed because I thought I was annoying him.

There were limited resources for Mexican parents to better understand their children's homework and the school curriculum. Many parents sought out homework help for their children, although space in affordable afterschool programs was extremely limited. As part of the larger collaborative action research project, weekly bilingual resource rooms were created at several elementary schools, providing a space where families could ask questions about homework and schooling. One father, who had participated regularly in these 
resource rooms with his wife during his daughter's kindergarten year, described how they helped them better understand the homework and how to help their daughter:

I think that was something fundamental in my daughter's development... We didn't have a clue about how schools were here. We didn't have a clue about how to help our daughter. First, we didn't know how to do the homework. The homework was in English. They didn't include any instructions we could understand. We didn't understand at first. Those meetings [the resource rooms] were crucial because we had doubts and didn't know who to go to. Since those meetings started, all the doubts began to diminish. At the end of the year-me and my wife were talking about this the other day -it became very easy for us. After those meetings I can say, "Homework is really easy" and my wife says "Can you see the difference between now and when school started?" It's just that we didn't know. If the teachers hadn't taken the time to teach us, we wouldn't have learned how to do the homework with our daughter.

Sobresalir was a means for teachers to hear directly from Mexican immigrant parents about homework challenges that educators had never imagined. Hearing parents' stories provided an alternative explanation for why students' homework, which may have appeared very simple to a native English speaker, was not always complete or correct. These counter-stories helped combat circulating discourses that characterize immigrant parents as uninterested in their children's schoolwork. As one teacher who viewed the film commented on a feedback sheet, "I assumed that many families weren't involved due to lack of caring, rather than frustration and anxieties due to language/culture barriers." By watching the film, teachers realized that homework was sometimes incomplete due to linguistic and cultural barriers rather than apathy. In addition to changing many teachers' beliefs that Mexican immigrant parents did not care about their children's education, it also led to action-such as school-based initiatives to create monthly meetings between grade-based teachers and parents (and interpreters) in which they now review key aspects of children's homework.

\section{Values}

A second theme that emerged from the parents' stories was their concern to instill strong values and monitor the moral development of their children; something called educación in many Latino communities. One couple, seated on their floral sofa with their newborn son in their lap, explained about their elementary school-aged daughter:

If she does something bad, we punish her. But we also don't like for people to mistreat her. She comes and tells us something, but then how can we believe her if she's a child? "He hit me." "OK, but tell me the truth, 
because if I go and it's not true, then you will be seen as a liar." We have always educated her to tell us the truth. "If you tell me the truth, then we will help you."

Many teachers were already aware of, and pleased with, Mexican immigrant parents' emphasis on good behavior. Educators had told us that the primary question most Mexican parents would ask at conferences was "How is my child behaving?" Teachers were frustrated, however, that Mexican immigrant parents tended to ask very few questions about academics, especially when their child was struggling. Parents' stories about educación in the film helped create space for teachers to talk about this concept, adding it to their own repertoires, and to acknowledge that many Latino families greatly respect the teacher's expertise in academic skill development and view their own responsibility as ensuring their child is bien educado [well educated and a moral person] in and out of school (Gallimore \& Goldenberg, 2001; Valdés, 1996; Valenzuela, 1999; Villenas, 2001). In this respect, as well, the film helped challenge some of the stereotypes that local teachers had about Mexican families. Parents' emphasis on educación provided insight into additional funds of knowledge (areas of cultural emphasis and expertise), which these families brought to their children's educational experiences and which teachers had not previously been aware of. One teacher wrote in her comments that "[t]he parents want to be involved in their children's education, but often lack the language and other resources to do so. Academics and behavior are important to them" (emphasis in original). Another teacher commented, "[t]he families featured had high expectations for their children's performance in school and also for teachers to help them and their children succeed. I'm afraid I was one who stereotyped that school wasn't so 'important' [to them]." Many teachers faced challenges communicating with newcomer parents because of language barriers, time restraints, and lack of familiarity with immigrants. This film was one of the first opportunities many local educators had to understand and appreciate what matters to Mexican immigrant parents.

Another topic of great importance to many immigrant parents was their children's safety at school and in the community. In the film, many families expressed concerns about their children being exposed to aggression and the schools' inadequate responses to bullying. As one father explained:

Well, there was an incident with my son. The bigger kids intimidated him. They started wanting to hit him, telling him, "Don't sit in that seat." So, for me it's very important because I don't want my son to experience aggression. If he doesn't have it at home, I don't want him to experience it elsewhere because a child who experiences aggression then commits aggression.

Many parents were not sure whom to turn to when their child shared stories of being bullied in school or on the bus, and they worried about the language barrier when communicating with teachers and the parents of English-speaking students who might be bullying their children. Many teachers were unaware of Mexican parents' concerns about their children's safety in school, especially at a time of 
heightened racial tension because of the strong anti-immigrant climate. Parents' counter-stories in Sobresalir opened teachers' eyes to legitimate concerns that they had not previously considered and gave them new repertoires to use with their Mexican immigrant students and families and to understand their strengths and values.

\section{Parent-Teacher Communication}

A third theme was parents' desire for increased parent-teacher communication. Although teachers often positioned Mexican immigrant parents as uncommunicative or shy, many Mexican immigrant parents spoke of their desire for increased communication with teachers. For example, as one mother of a middle-school student humorously explained:

Your daughter could leave your house dressed one way but at school they have clothes in their backpacks. And they get dressed up in short skirts and provocative blouses. The teacher must be mindful. Inspect their backpacks. Their privacy isn't the most important thing. Open their backpacks and everything. Look through their notebooks and see what they have. Because as a parent you say, "Oh my son, so cute... my love, my girl." Yeah-at home. But they change when they leave the house. They're different, so parents and teachers need to be vigilant with them.

This parent, and many others, strongly felt that parents and teachers have to collaborate in order to ensure that children (especially teenagers) are acting appropriately. The film helped teachers recognize that Mexican immigrant parents often do not condone some children's questionable behavior because parents are generally unaware of it. Although this challenge is certainly not unique to immigrant families, the difficulties in parent-teacher communication are more serious for a large Spanish-speaking population in a district with few bilingual adults.

This theme was addressed in many teachers' comments after seeing the film, and some vowed to take action and increase their attempts to communicate with Spanish-speaking parents. For example, one teacher commented, "[k]nowing how hard these parents push their kids towards academic success will make me want to take the extra time to reach out so we can work together" and another wrote, "I shouldn't shy away from contact just because it isn't easy. Just because it is difficult, doesn't mean it isn't wanted."

Many parents also encouraged teachers to reach out sooner when they were having difficulties with children, because nobody knows a child better than his or her parents. As one mother explained:

They're kids. So one has to have more patience with them. Every child, every person has a bad side and there is a way to win over a child. So if the teachers have a problem in that regard the parents would know their 
children better and they would be able to help them. So it would not be so complicated for the teacher.

Many parents strongly encouraged teachers to use them as resources and to get in touch immediately when they were experiencing a challenge with their child. For teachers, who were often unsure of how to approach Spanish-speaking parents, this advice helped encourage many of them to make contact. One teacher reflected on her previous attempts to communicate with Spanishspeaking families and the need for change: "Don't fear contacting the parentmake every effort. I have been shortchanging parents who do not speak English."

Other parents spoke of their appreciation for teachers who had reached out to them to learn more about a child, as this mother described:

I wrote the letter telling her all the details regarding my son and she sent her thank you. You can see the communication here, right? It's good communication because the parent and the teacher are working together. I'm home and the teacher is in school. And there is a greater possibility that the children learn more.

As in Doucet's (2011) work with Haitian parents, in Marshall immigrant parents overwhelmingly agreed that they would like more communication with teachers about their child — not less, as many teachers had assumed. In addition, several parents had suggestions about creating opportunities for parents to visit during the school day and thereby to become more familiar with school activities and the teacher. Parents explained that they know teachers are very busy, but they suggested that perhaps one afternoon a month could be designated for parents to visit quietly and observe what is going on. They felt this would be a useful way to understand better what their children were experiencing and talking about at home. In contrast, teachers often mistakenly believed that immigrant parents do not like coming to their children's schools. Parents' stories in Sobresalir countered this myth. Although parents sometimes do not attend because events are scheduled at times when they have to work, or because of difficulties getting to the school, these parents made clear that they wanted to know more about their children's schools. Even in schools where Mexican immigrant parents did attend many events, the parents' stories suggested that they wanted to learn more about their children's schooling firsthand and to serve as resources for the school to learn more about their own backgrounds.

Several parents spoke of wanting to visit classrooms to teach about their own cultural backgrounds. As one mother explained, seated in a chair in her living room:

Of course I would like the teachers to learn. You know that if they start to work with the Latino culture they will come to learn that we Latinos, Mexicans as well as those from other countries, have very different cultures, right? They are very beautiful cultures that I would like the teachers to learn. Or maybe they can call on us parents to say, "Come and teach us something new." We will gladly go... We could be from the same country [Mexico], but we have very different cultures. 
This mother's comment helped raise teachers' awareness of the important differences between Latino and Mexican cultures, something of which many were unaware. Her point highlights how immigrant parents, even from the same country, may have different repertoires. This mother's comments also led to changes in action: At least one first-grade teaching team took up her suggestion and invited different parents to teach about anything of their choice, and several families from Mexico taught about their local traditions. In 2011 one elementary school started inviting parents to visit one afternoon a month, as suggested by another parent. In a place where teachers and administrators are eager to foster stronger relationships with Spanish-speaking families, especially once they have a clearer understanding of the unique resources that parents bring to their children's education, parents' suggestions have led to concrete changes in the engagement opportunities available to Spanish-speaking families in Marshall.

\section{Equitable Schooling}

A final theme involved parents' hopes that their children not be treated less favorably than others. Keenly aware of the strong anti-immigrant discourses circulating in the media and some segments of the local community, as well as their own experiences with unequal treatment as Spanish-speaking immigrants, some parents articulated hopes that their children would not suffer from discrimination within local schools. As one mother said:

I hope they [teachers] help them get more involved in this country so that they have the same opportunities as everyone else. For them [teachers] not to put them [students] aside but get them more involved, for them to give the same preference they give the others from here.

Overall, parents were very satisfied with the teachers and local schools, and they often complimented local educators in the film. As one mother put it:

I like it. I like how they are doing it here in school. I like that they get attention. They take good care of them. They show a lot of concern for the kids. This is what I like.

The interviews do not give the impression that parents feel their children have experienced extensive discrimination within local schools, but they nonetheless ask teachers to ensure that unequal treatment not occur. This was especially important to parents because, as the economic situation became more difficult and the local treatment of immigrants worsened between 2008 and 2010, parents often justified their decision to endure and not return to Mexico by citing what Michael, Andrade, and Bartlett (2007) call the "opportunity discourse," staying for the better educational opportunities their children have in the U.S. As one teacher commented after viewing the film, "It's easy to assume that these parents don't care about their children's education. This is obviously not the case. Through this film I realized these parents have the same hopes/dreams for their children that I have for mine. I could feel their frustrations, fears, and love." Many 
teachers commented on how, through these parents' stories, they realized that immigrants and longstanding residents share similar goals for the students and that, as parents, they have a great deal in common. As one teacher eloquently wrote, "Latino parents are like all parents - they want the best for their child, they want to feel respected and heard, they want to be equal partners. Treat them this way and positive relationships will develop." After hearing individual parents' stories and learning about their hopes and dreams for their children, teachers were able to view Mexican immigrant parents similarly to themselves. This contrasts with widely circulating discourses about Mexican immigrants that tend to position them as harmful masses (e.g., Santa Ana, 1999) or dehumanize them in ways that help justify harsh deportation practices (e.g., Dick, 2011). In addition, most teachers responded positively about their own need to act and change, resolving to reach out more explicitly to Spanish-speaking families, to find ways to collaborate with them despite the language barrier, and to recognize the goals and values they have in common as they work together to help students succeed.

\section{Conclusions}

We have described the creation and contents of a collaborative film that illustrates Latino immigrant parents' perspectives on local schools in one New Latino Diaspora community. This project is an example of Doucet's (2011) call for alternative parent involvement practices that can engage minority communities often marginalized by traditional approaches. As educational researchers who are not professional filmmakers, we used low-budget technology and drew on a few university resources to create a 27-minute film. Sobresalir grew out of our hope that a simple film could deepen understanding and relationships among educators and immigrant families - something that it has apparently achieved. The medium of film was a creative way to present immigrant parents' voices and bring their funds of knowledge to a large audience of local educators. Locally produced films appear to be a promising medium for counter-storytelling and for the professional development of educators who work with immigrant children and their parents.

Sobresalir presents immigrant parents' voices, which are rarely heard in traditional parent involvement initiatives. Parents' counter-stories raised teachers' awareness about many topics of concern. This awareness, and the critical reflection facilitated by discussion and writing during professional development sessions, led to action for many individual teachers - such as resolving to become more proactive in personal communication with Mexican immigrant parents. The themes from this film also led to collective action within the schools, including the implementation of several parent suggestions that are communicated in the film. Although the film has been well received in other settings outside Marshall, its embeddedness in the local context has been crucial to its educational success. The process of working with immigrant parents in 
producing the film has helped them claim more voice in their interactions with educators The fact that educators see parents from their own schools in the film has made it more effective. Other schools hoping for similar results might consider producing films of their own.

\section{Notes}

1. Sobresalir means "to get ahead" and is a term that Mexican immigrant parents used when talking about their hopes and dreams for their children.

2. All excerpts and quotations were originally in Spanish. The film presents the original Spanish in the parents' voices, with English subtitles.

\section{References}

Ceballo, R. (2004). From barrios to Yale: The role of parenting strategies in Latino families. Hispanic Journal of Behavioral Sciences, 26, 171-186.

Chavkin, N. F. (1989). Debunking the myth about minority parents. Educational Horizons, 67(4), 119-123.

Delgado, R. (1989). Storytelling for oppositionists and others: A plea for narrative. Michigan Law Review, 87, 2411-2441.

Delgado, R., \& Stefancic, J. (2001). Critical race theory: An Introduction. New York: New York University Press.

Delgado-Gaitan, C. (1991). Involving parents in schools: A process of empowerment. American Journal of Education, 100(1), 20-46.

Delgado-Gaitan, C. (2001). The power of community: Mobilizing for family and schooling. Lanham, MD: Rowman \& Littlefield Publishers.

Delgado-Gaitan, C. (2004). Involving Latino families in schools: Raising student achievement through home-school partnerships. Thousand Oaks, CA: Corwin Press.

Dick, H.P. (2011). Making immigrants illegal in small-town USA. Journal of Linguistic Anthropology, 21(S1), E35-E55.

Doucet, F. (2011). Parent involvement as ritualized practice. Anthropology and Education Quarterly, 42(4), 404-421.

Gallimore, R., \& Goldenberg, C. (2001). Analyzing cultural models and settings to connect minority achievement and school improvement research. Educational Psychologist. Special Issue: The Schooling of Ethnic Minority Children and Youth, 36(1), 45-56. 
Gallo, S., \& Wortham, S. (in press). "Increasing 'parent involvement' in the new Latino diaspora." In E. Hamann, S. Wortham, \& E. Murillo (Eds.), Revisiting education in the new Latino diaspora. Charlotte, NC: Information Age Publishing.

Gouveia, L., Carranza, M., \& Cogua, J. (2005). The great plains migration: Mexicanos and Latinos in Nebraska. In V. Zúñiga \& R. Hernández-León (Eds.), New destinations. (pp. 23-49). New York, NY: Russell Sage Foundation.

Grey, M. A., \& Woodrick, A. C. (2005). "Latinos have revitalized our community": Mexican migration and Anglo response in Marshalltown, lowa. In V. Zúniga \& R. Hernández-León (Eds.), New destinations: Mexican immigration in the United States (pp. 133-152). New York, NY: Russell Sage Foundation.

Gutiérrez, K. D., \& Rogoff, B. (2003). Cultural ways of learning: Individual traits or repertoires of practice. Educational Researcher, 32(5), 19-25.

LeCompte, M., \& Schensul, J. (1999). Analyzing and Interpreting Ethnographic Data. Ethnographer's Toolkit \#5. Walnut Creek, CA: Alta Mira.

Mangual Figueroa, A. (2011). Citizenship and education in the homework completion routine. Anthropology \& Education Quarterly, 42(3), 263-280.

Michael, A., Andrade, N., \& Bartlett, L. (2007). Figuring "success" in a bilingual high school. Urban Review 39(2):167-189.

Millard, A., \& Chapa, J. (Eds.) (2004). Apple pie and enchiladas: Latino newcomers in the rural Midwest. Austin, TX: University of Texas Press.

Moles, O. (1993). Collaboration between schools and disadvantaged parents: obstacles and openings. In N. F. Chavkin (Ed.), Families and schools in a pluralistic society (pp. 21-52). Albany, NY: State University of New York Press.

Moll, L., Amanti, C., Neff, D., \& Gonzalez, N. (1992). Funds of knowledge for teaching: Using a qualitative approach to connect homes and classrooms. Theory in Practice, 31(2), 132 - 141.

Moll, L., \& Gonzalez, N. (2004). Engaging life: A funds of knowledge approach to multicultural education. In J.A. Banks \& C.A. Banks (Eds.) Handbook of research on multicultural education ( $2^{\text {nd }}$ ed., pp. 699-715). San Francisco, CA: Jossey-Bass.

Murillo, E. (2002). How does it feel to be a problem?: "Disciplining" the transnational subject in the American south." In S. Wortham, E. Murillo, \& E Hamann (Eds.), Education in the new Latino diaspora: Policy and the politics of identity. Westport, CT: Ablex Press.

Rich, B. L., \& Miranda, M. (2005). The sociopolitical dynamics of Mexican migration in Lexington, Kentucky, 1997 to 2002: An ambivalent community responds. In V. Zúñiga \& R. Hernández-León (Eds.), New destinations: 
Mexican immigration in the United States (pp. 187-219). New York, NY: Russell Sage Foundation.

Rymes, B. (2010). Classroom discourse analysis: A focus on communicative repertoires. In N. Hornberger, \& S. L. McKay (Eds.), Sociolinguistics and language education (pp. 528 - 546). Bristol, UK: Multilingual Matters.

Santa Ana, O. (1999). 'Like an animal I was treated': Anti-immigrant metaphor in US public discourse. Discourse \& Society, 10(2), 191-224.

Solorzano, D. G., \& Bernal, D. D. (2001). Examining transformational resistance through a critical race and LatCrit theory framework: Chicana and Chicano students in an urban context. Urban Education, 36(3), 308-342.

Suárez-Orozco, C., \& Suárez-Orozco, M. M. (2001). Children of immigration. Cambridge, MA: Harvard University Press.

Torres-Guzmán, M. (1991). Recasting frames: Latino parent involvement. In M. McGroarty \& C. Faltis (Eds.), Languages in school and society: Policy and pedagogy (pp. 529-552). Berlin, Germany: Mouton.

Trueba, E. T. (1999). Latinos unidos: From cultural diversity to the politics of solidarity. Lanham, MD: Rowman \& Littlefield.

U.S. Census Bureau (2010). American fact finder: Marshall borough, Pennsylvania.

Retrieved 16 March 2010 from http://factfinder2.census.gov/faces/ tableservices/jsf/pages/productview.xhtml?fpt=table

Valdés, G. (1996). Con respeto: Bridging the distances between culturally diverse families and schools: An ethnographic portrait. New York, NY: Teachers College.

Valenzuela, A. (1999). Subtractive schooling : U.S.-Mexican youth and the politics of caring. Albany, NY: State University of New York Press.

Villenas, S. (2001). Latina mothers and small-town racisms: Creating narratives of dignity and moral education in North Carolina. Anthropology \& Education Quarterly, 32(1), 3-28.

Wortham, S., Murillo, E., \& Hamann, E. (2002). Education in the new Latino diaspora: Policy and the politics of identity. Westport, CT: Ablex Press.

Wortham, S., Mortimer, K., \& Allard, E. (2009) Mexicans as model minorities in the new Latino diaspora. Anthropology and Education Quarterly, 40(4), 88-405.

Zúñiga, V., \& Hernández-León, R. (2005). Introduction. In V. Zúñiga \& R. Hernández-León (Eds.), New destinations: Mexican immigration in the United States (pp. xi-xxix). New York, NY: Russell Sage Foundation. 